\title{
The Pre-Production Plans on Designing a Promotional Video for Project-based Language Learning: A Case Study with Smart Toilets
}

\author{
Debopriyo Roy*, Hirotaka Kosai and Kazuma Takai \\ The Univers ity of Aizu, Aizuwakamatsu-shi, Fukushima, Japan
}

\begin{abstract}
This pilot project undertook an effort to understand how the pre-production plans on designing a promotional video in a project-based language learning classroom could be unveiled with undergraduate EFL computer science junior-level students. The central idea of the project was to explore the efficacy of digital storytelling as a method for developing professional communication skills in English. The specific case study chosen for the project was on intelligent toilets, and the pre-production movie design activities as assignments were designed in the syllabus as a community outreach effort in trying to promote awareness about intelligent toilets as a commercial product, and the necessity and benefits of intelligent toilets for consumers who might not be aware of it's reach. Assignments such as designing storyline and screenplay, print and video poster design, visual storyline with concept mapping, storyboarding and conference presentation design and delivery not only focused on understanding how students handle different design and analysis software, and technical documentation in a group setting, but also the extent to which they could successfully work with their team collaboratively, and in the process improve professional communication. The project could not explicitly and objectively measure the learning outcomes for professional communication, but it helped us explore the extent to which the group assignments requiring substantial group communication and coordination could be worked through successfully, and students' self-reported impression about the course materials, in general, and the working dynamics of the group. It's an established fact that successful group communication and coordination, and such group-based technical communication activities require multiple interactions, iterations and repeated and prolonged exposure. However, within the limited scope of this pilot project, the researchers could identify moderately successful efforts being made both for the assignments and in terms of the team effort.
\end{abstract}

Keywords: Movie, Promotional Video, Design, Professional Communication, Intelligent Toilet, Teamwork

\section{Introduction}

This preliminary paper outlined the design and efficacy of the pre-production communicative and collaborative movie design activities in an EFL project-based language learning classroom. The content area focused on designing a promotional video on intelligent toilets. Using videos to promote creativity in a foreign language classroom has been widely researched. This pedagogical model also supports a soft-CLIL approach for language teaching. The entire idea behind video-making, and specifically promotional video design in a language classroom as a pedagogical tool is to promote creativity, meaning-making, and "fostering dialogue among students" [1, 2]. Film, video, television, and digital media have been integral to the development of new pedagogical theories and practices, globalization processes, and identity and community formation. Yet, Brian Goldfarb argues, the educational roles of visual technologies have not been fully understood or appreciated [3].

With the development of learner autonomy in CALL disciplines, video design pedagogy has been adopted as a constructivist perspective on education [4]. Student produced videos in EFL programs are increasingly becoming an accepted and common theme $[5,6]$. For this project, we have adopted a similar approach where students in a technical university computer science program, as part of a project-based language learning (PBLL) class, designed a documentary-styled promotional video focused on a specific choice of intelligent/smart product. The idea behind the project is to teach technical writing, new media design (with information design), and entrepreneurial thinking with active language learning.

*Corresponding author: 


\section{Review of the Literature}

Communication research and topics on intercultural relations have some mention of using promotional videos in an intercultural classroom context to receive feedback. However, there is hardly any EFL teaching content or courses being discussed in the language teaching literature which is focused on e-commerce materials, marketing communication using video-making as a pedagogical structure and/or entrepreneurship as a theme. With the increasing need for soft skills development for engineering and computer science students taking language courses in EFL contexts, this genre of language teaching where e-commerce, marketing, entrepreneurship and other related skills are advocated are becoming increasingly more important and the need for the hour. Other models of entrepreneurship-based language teaching such as with 3D-printing [7,8], crowdsourcing and social network analysis [9] have suggested the use of diverse community and Industry 4.0-based tools and systems for language learning in EFL contexts. Movie production for language learning, although researched quite extensively in EFL contexts, hasn't put any focus on linguistic entrepreneurship, or the technical writing (procedural, business communication etc.) aspects that are so relevant for technical students preparing for the job market.

E-commerce cannot do without video content for promotional purposes [10]. To promote the concepts of "value" and "value creation", promotional videos in organizations have become an absolute necessity from the marketing perspective. Online promotional videos for smart products such as smart toilets, as argued in this paper are a form of institutional and product branding and marketing that construct the product experience in a variety of ways. Storytelling represents an extensive and rich body of research in branding through promotional videos. Research [11] has clearly suggested that DMC (Digital Marketing Communications) in this era occupies one of the most important industrial marketing communication tools, but companies have not yet realised or used it to its full potential. Second, firms use DMC to enhance customer relationship communications, support sales and create awareness. Third, firms have not used social media tools, such as YouTube, Facebook etc. as a part of DMC as widely as traditional digital tools. An example case comes from research on the positive impact of tourism advertisement promotional videos on young adults, influencing decision-making $[12,13]$. In an EFL classroom, the production of such marketing videos could also help with the publicizing of the videos in orientations, flipped classrooms, social media, and other appropriate venues, creating a brand genre and community outreach of an idea or product outside the scope of corporate endorsement.

We used the specific case of smart products such as a smart/intelligent toilet because it's trendy, and focused on the POP-framework, which discusses how People, Objects and the Physical world interconnect with each other and how it results in an increasing amount of connected data [14]. An intelligent product consists of three different ideas, namely (1) what is the intelligence of the product (2) what is the location of intelligence and (3) whether the product consists of a single entity or is it a composition of different entities [15]. Student work on video production has been designed to reflect such understanding of content and concepts.

Our future research on smart toilet promotional campaigns using marketing videos would also help investigate the potential impact of IoT and smart products on consumer behavior and firm strategies. Such understanding and related investigation could be impressive in a project-based language learning context, and could help promote entrepreneurial thinking in a language teaching context.

This paper is focused on discussing an EFL project-based language learning (PBLL) context where two separate student groups with 6-7 members (undergraduate third-year computer science students in a computer science university), planned on creating a 30-minutes promotional video on smart toilets, based on their research of the product. The paper will focus on how the two promotional videos designed were planned on being different from each other in terms of (1) goal (2) direction (3) tone (4) media focus, and (5) video production. The orientation of the promotional video was pre-decided in the classroom after intense discussion, based on the 5 criteria mentioned above. The videos were planned to be designed using different software such as Animoto, Adobe Spark, iMovie, promo.com, etc., at the initial stages, and iMovie and Final Cut Pro for the final version. Students also discussed how their planned movie could be potentially peer-reviewed on the following rubric: https://www.sausd.us/cms/lib/CA01000471/Centricity/Domain/494/Video.pdf.

\section{Project Highlights}

This entire project was focused on teaching meaningful learning (TML) with the course syllabus focusing on designing and organization of the learning environment, support and guidance for meaningful learning, process characteristics and expected outcomes as is seen in the model below. Figure 1 demonstrated the PBL model that was referenced actively as an underlying model driving this pre-production movie design plan. 


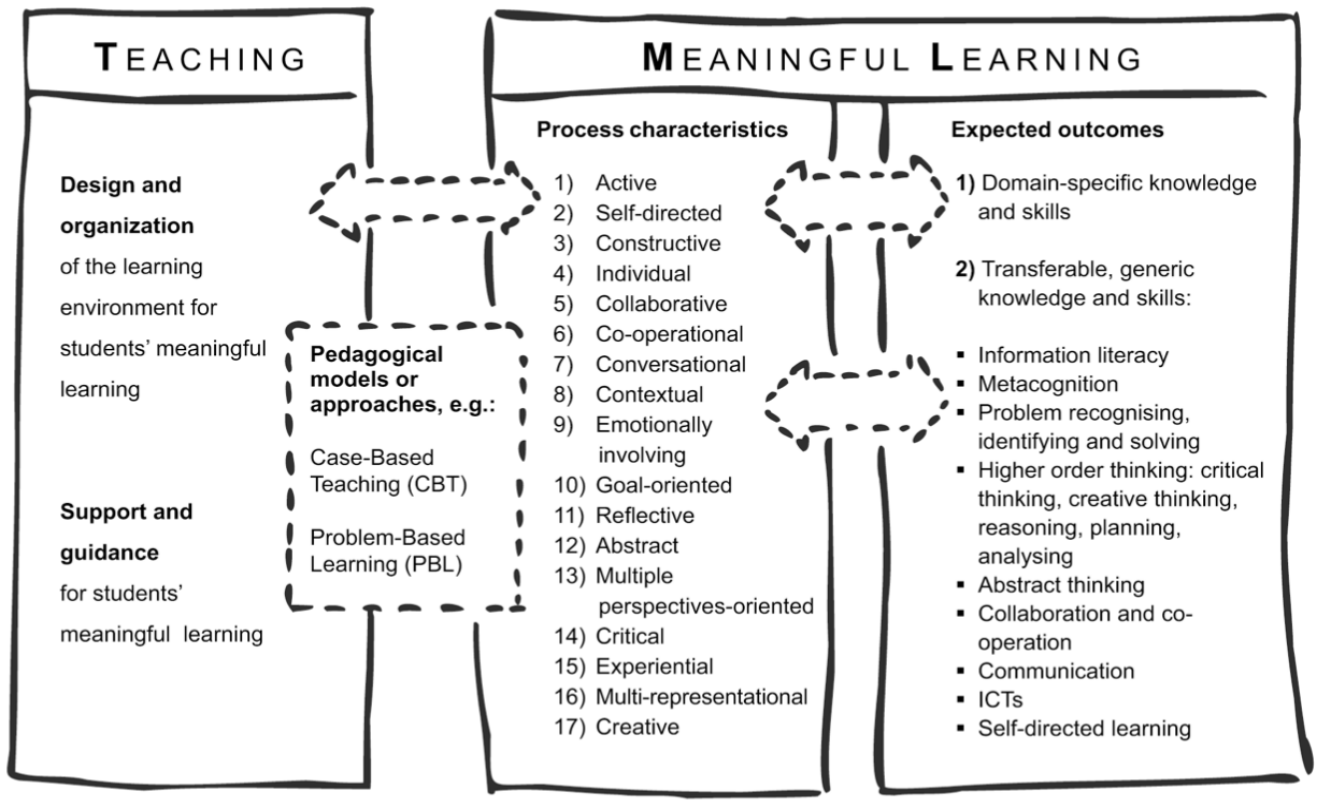

Figure 1. The TML Model (Hakkarainen, 2007, 2009; Hakkarainen, Saarelainen, \& Ruokamo, 2009) Introduced in a Promotional Video Production Context

\section{Major Assignments \& Pre-Production Design Outcomes}

As part of this initiative, we taught a third-year English elective course with the title Design of Movies for Professional Communication. In this interesting course, students were asked to design the script for a full-fledged movie documentary on Smart Toilet Interface. Students during the 7-week quarter went through different pre-production scripts design, including semantic models (language use) for linguistic application, developing the ontology (structure and links) of different variants of information and linkages which could be used to develop a proper thoughtful storyline and an informative script which will both be informative, persuasive, demonstrative and procedural. Different semantic models, at elementary level, including concept mapping,video design and infographics software were used for information management purposes. We had two groups of 8 members each $(\mathrm{N}=16)$, working on the topic of designing the pre-production movie script. Significant time during this course was spent on understanding the basics of workflow management for a movie production project.

In terms of objectives \& attainment goals, the following outcomes were attempted:

1. Develop a sense of how to analyze and search for information in the context of movie design planning

2. Develop a sense of how to manage different workflow and teamwork in the context of the movie workflow design 3. To analyze specific audiences and rhetorical, informational, demonstrative, and other situations in the design of a corporate movie documentary, through script design, dialogue writing, and subtitling

4. Understand how to use various kinds of information modeling genres and linkages when developing an ontology for information delivery

It's important to understand that due to time constraints some of those activities such as dialogue writing and subtitling could not be achieved with reasonable satisfaction.

Table 1 highlighted the major assignments for the course. These assignments were discussed in class both within and across groups, and specific instructions and explanations were provided with the screenplay worksheet and other assignments. Table 1 highlighted a summary of the lecture materials and class activities. 
Table 1. Project Details

Project Details - Lecture Materials/Discussions

An intelligent product consists of three different ideas, namely:

(1) what is the intelligence of the product

(2) what is the location of intelligence, and

(3) whether the product consists of a single entity or is it a composition of different entities

- Each group must plan on creating a 30-minutes promotional video on smart toilets, based on their research of the product.

- The paper will focus on how the two promotional videos designed were different from each other in terms of (1) goal (2)

direction (3) tone (4) media focus, and (5) video production.

- The videos are to be designed using different software such as Animoto, Adobe Spark, iMovie, promo.com, etc.

This paper will outline the ideas for the smart toilet project, focused on two major companies -

- Toto - a Japanese company specializing in toilet design, and

- Kohler - a US-based company specializing in bathroom, and kitchen-based intelligent products.

The promotional videos for the two groups will highlight the following:

- (1) the concept of smart toilets

- (2) the company products

- (3) the technological innovations

- (4) the market for the products in Asia, the US, and the UK

- (5) the different benefits of using a smart toilet, including the community and health benefits

- (6) how to reach out to poorer nations with such energy-efficient initiatives.

Major Assignments: The course project will discuss different student-led team initiatives with smaller sub-projects:

- (1) designing storyline and screenplay

- (2) designing an online movie poster (print and video poster)

- (3) the visual storyline with concept mapping

- (4) storyboarding design

Further Class Discussions:

- (5) using production management software (https://www.studiobinder.com/) and

- (6) final movie design with iMovie or Final Cut Pro.

Group A Focus: Marketing the concept of intelligent toilets to customers worldwide.

- product features

- customer convenience

- price advantage (balance between quality-service-pricing)

- after-sales service guarantee (installation, maintenance contract, etc.)

- cost-effectiveness

Group B Focus: Design and planning on explaining the technologies associated with the concept of intelligent toilets.

- Internet of Things

- Smart home technology

- Voice commands \& Mobile Apps

- $\mathrm{AI}$ and automation

- Robotics

- Health-focused technology

Terms Identified; intelligent toilet reference materials (text and video links); seven stages of movie production, screenplay design; sketchboarding and concept /mind mapping software, storyboarder software, studiobinder workflow management

\subsection{Assignment 1: Icebreaker (Individual Assignment)}

Please answer each question in about 50 words. Write in your own words.

- Q1. Why are you interested in learning about movie production? Why is movie production interesting?

- Q2. Do you think video production is an important skill to develop for today's industry?

- Q3. Please watch the video on smart toilets. What do you find interesting about the video?

- Q4. Explain some of the interesting content mentioned in the video.

- Q5. Do you think some of these smart toilets are too futuristic in the context of the world (not Japan)?

The students in most cases, answered the above questions reasonably well, demonstrating reasonably acceptable ability to express their positive feeling about the topic, willingness to go through the understanding of the topic for movie design and social awareness purposes, going through the stages of the pre-production movie scripting, and showing ability to hold an opinion on a socially important matter, based on which the movie script would be designed. It also showed reasonable ability to watch an English video, understand it's content and reflect on it. Next, we started with the major group assignments, which also helped us understand the group dynamics, ability for professional communication in a team context with such low-moderate ability in English, and also team working 
efficiency, with the range of assignments on which team members collaborated. It's important to mention here that for many of these assignments, students in a team were categorically asked to collaborate on a single document in Google Drive, as much as possible. Even when some students were responsible for working on different software for the given assignments, they were asked to import the document in Google Drive, so that everyone can comment, edit, or recommend changes as much as possible. Since the focus of the course remained on professional communication in English, and project based language learning through content area emphasis as could be typically seen in soft-CLIL courses, group collaboration, and coordination was the key which could make or break a group. It was a learning experience for the group members who in most cases, did not have such an experience working through a myriad of complex activities requiring intense collaboration at all levels. For each major assignment, students were asked to identify the role they played when completing the assignment.

\subsection{Assignment 2: Introduction to Storyline \& Screenplay}

This assignment was the first stage in creating a pre-production outline of the video storyline with screenplay design. It's important to see the assignment scores in light of the fact that multiple iterations are required to make such a storyline feasible, reasonable and effective in the content of movie design. Students, in a 7-week quarter system, unfortunately do not have such time to run through multiple iterations.

Table 2: Assignment 2 Outline

\begin{tabular}{|c|c|}
\hline $\begin{array}{l}\text { Section \# 1: } \\
\text { (Ideally, } \\
\text { everyone } \\
\text { should be part } \\
\text { of the } \\
\text { discussion and } \\
\text { text } \\
\text { contribution) }\end{array}$ & 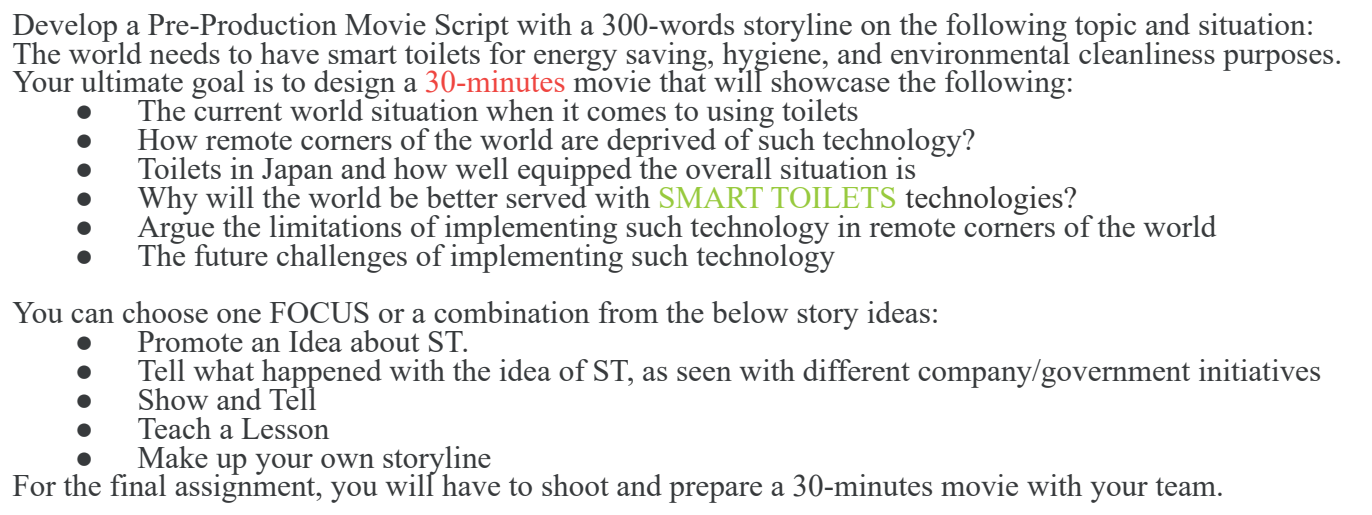 \\
\hline Section \# 2: & $\begin{array}{l}\text { Watch the screenplay tutorial video carefully, read the subtitles and the transcript. } \\
\text { Can you divide your storyline in terms of ACTS? Let's imagine your movie is } 30 \text {-minutes long. Divide the } \\
\text { story into } 3 \text { ACTS (BEGINNING, MIDDLE, \& END). Write a } 40-50 \text { words paragraph for each (beginning, } \\
\text { middle, and end). }\end{array}$ \\
\hline Section 3: & $\begin{array}{l}\text { omplete the Screenplay Design Worksheet as much as possible. Upload PDF in Moodle. Fill out the } \\
\text { orksheet using https://www.digisigner.com/free-electronic-signature/ }\end{array}$ \\
\hline
\end{tabular}

Table 3. Assignment 2 - Score (Out of 20) - Each Category with 5 Points

\begin{tabular}{|l|l|l|l|l|}
\hline Team & Section 1 - Storyline & Section 2 - Three Acts & $\begin{array}{l}\text { Section 3 - Screenplay Design } \\
\text { Worksheet (Stage 1) }\end{array}$ & Team Coordination Score \\
\hline A & 3 & 2.5 & 2 & 2 \\
\hline B & 4 & 4 & 4 & 4 \\
\hline
\end{tabular}

- The team coordination score was given independently and not added immediately to the total score for the assignment

- Not all students in the same group may have received the same grade due to their ability/inability to post the assignment in Moodle based on instructions given

Table 3 data highlights the fact that the pre-production movie script authoring, the screenplay design, and the screenplay worksheet assignment (evaluated as a first draft) was performed better by Team B as compared to Team A. Mostly, the score difference resulted from the depth of the storyline, consideration of the guidelines mentioned in 
the assignment, ability to consult with class instructor and peers when completing the screenplay design worksheet, and the team coordination as observed in class.

\subsection{Assignment 3: Print \& Video Posters}

With this assignment with poster design for movies - both print and video, the idea was to see how students market the idea of the posters (the content, the design etc.) at a preliminary level. There wasn't much opportunity to improve the design iteratively based on feedback due to the fast-track pace of the class, and with the idea to expose students to the entire gamut of activities related to the pre-production movie design.

Table 4: Assignment 3 Outline

SECTION 1: Based on Assignment \# 2 movie ideas for your group, design a PRINTABLE movie poster using CANVA. Design TWO DIFFERENT KINDS of posters. 2-student sub-groups will be working on EACH poster.

SECTION 2: Create your VIDEO movie poster for publicity in the BOX OFFICE. A 4-student sub-group will be working on the movie poster. https://spark.adobe.com/make/posters/movie-posters/

Consider the following points when designing your VIDEO poster.

A. What is special about the storyline?

B. What is the role of the central characters/objects in the movie?

C. What is there for the audience to learn from the movie? How does it relate to their life, in general?

D. What kind of person would likely be interested to watch your movie?

E. Think about an example of another movie which you think follows the same idea as yours. In other words, think about another movie that influences your thought process for this movie.

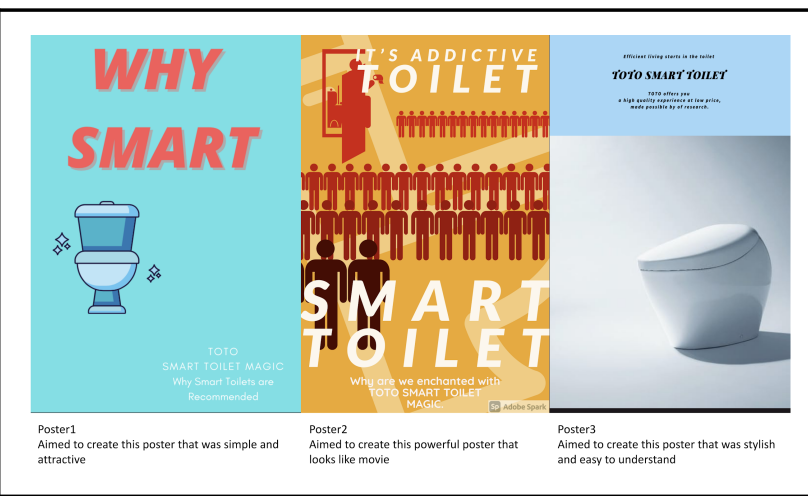

Team A

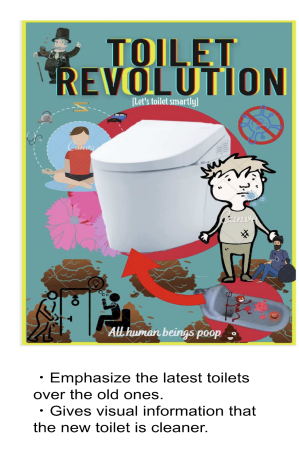

the new toilet is cleaner.

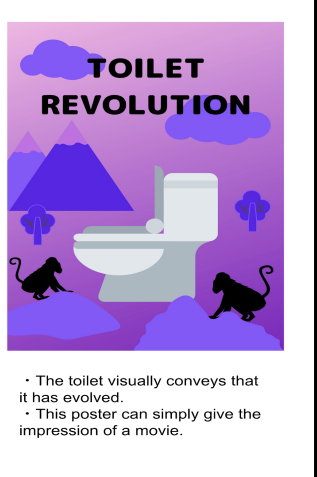

Team B

Figure 2. Intelligent Toilet Print Posters Done by Teams A \& B

Table 5. Assignment 3A - Poster Presentation with Canva - Evaluation Rubric - Score (Score out of 20)

\begin{tabular}{|l|c|c|}
\hline Criteria & Team A & Team B \\
\hline Layout/Design & 2.5 & 3 \\
\hline Content & 2.5 & 3 \\
\hline Delivery & 3 & 2.5 \\
\hline Result & 2.5 & 2.5 \\
\hline Impact & 2.5 & 2.5 \\
\hline
\end{tabular}

The Table 5 data demonstrates that there isn't much difference between the total scores for Group A and Group B with both teams securing almost equal total points. The performance was at best, moderate for both the teams. The most difficult area was lack of content, and the ignorance about the possible impact it could have on the audience.

With the Adobe Spark promotional video design assignment (Table 6), the performance was clearly better for Team $\mathrm{B}($ total score $=14.5)$ as compared to Team A (total score $=11)$, and that's mainly because of the lack of information 
and content, and the inability to perform thinking/inquiry/analysis about the content and how to deliver it successfully in a video-based medium. We did not adopt a standard video evaluation rubric for this exercise. Rather, we used a sales pitch presentation evaluation rubric to get the true essence of the purpose for designing the video. https://freefoto.ca/marketing-mix-project-rubric-rubric-for-marketing-mix.html

Table 6. Assignment 3B - Sales Pitch Presentation with Adobe Spark - Evaluation Rubric - Score (Score out of 20)

\begin{tabular}{|l|c|c|}
\hline Criteria & Team A & Team B \\
\hline Information/Content & 2 & 3 \\
\hline Relevance to Curriculum & 3 & 3 \\
\hline Thinking/Inquiry/Analysis & 2 & 2.5 \\
\hline Creativity/Style & 2 & 3 \\
\hline Impact & 2 & 3 \\
\hline
\end{tabular}

Outstanding $=4$, Very Good $=3$, Good $=2 ;$ Acceptable $=1$ and Unacceptable $=0$

\subsection{Assignment 4: Visual Storyline with Concept Mapping}

This was a concept mapping assignment (Table 7) to effectively explore if students were able to successfully map the ideas and make connections between several ideas and characters, and events that they planned to demonstrate in the promotional video.

Table 7. Assignment Outline

\begin{tabular}{|l|l|}
\hline \multicolumn{1}{|c|}{ Task } & \multicolumn{1}{c|}{ Explanation } \\
\hline A & $\begin{array}{l}\text { Visually design the basic movie idea using SketchBoarding Software; visually demonstrate how the different } \\
\text { people, objects, and tasks in the movie are related to each other. Examples of concept mapping provided }\end{array}$ \\
\hline B & Develop the complete storyline visually in detail using MINDMEISTER Mind-Mapping Software. \\
\hline C & $\begin{array}{l}\text { Complete the Screenplay Design Worksheet with more details (based on Class 2-3 assignment) (Convert into } \\
\text { a.docx file, complete it, save it asDF and upload) }\end{array}$ \\
\hline
\end{tabular}

In trying to understand, students' ability to reflect on major concepts and represent it successfully and meaningfully in the Sketchboard and the Mind Map, we primarily adopted the McMurray evaluation model (2014) [16], but also referenced all other models mentioned in Coutinho (2014) [17].

Table 8 data showed that overall, Team B (total score $=13$ ) has performed better than Team A (total score $=9.5)$ and we can see why it's possibly the case. The performance with Mindmeister was moderate at best for both the groups, but the difference in score resulted more from the performance with the Sketchboarding software. The breath, interconnectivity and use of descriptive links was more robust for Team B than for Team A.

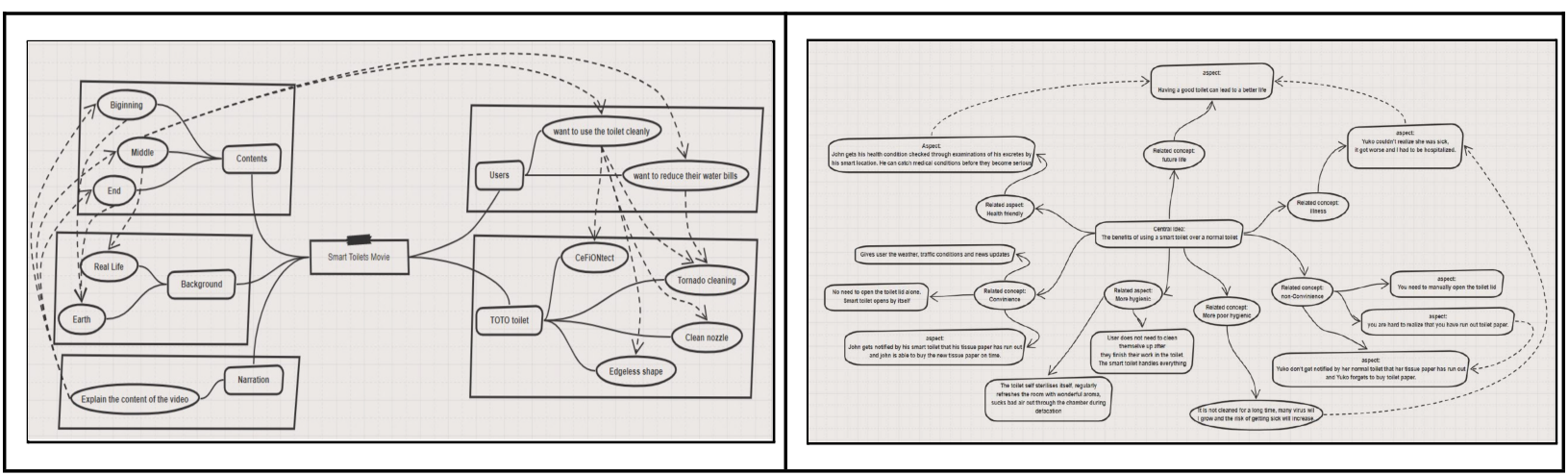




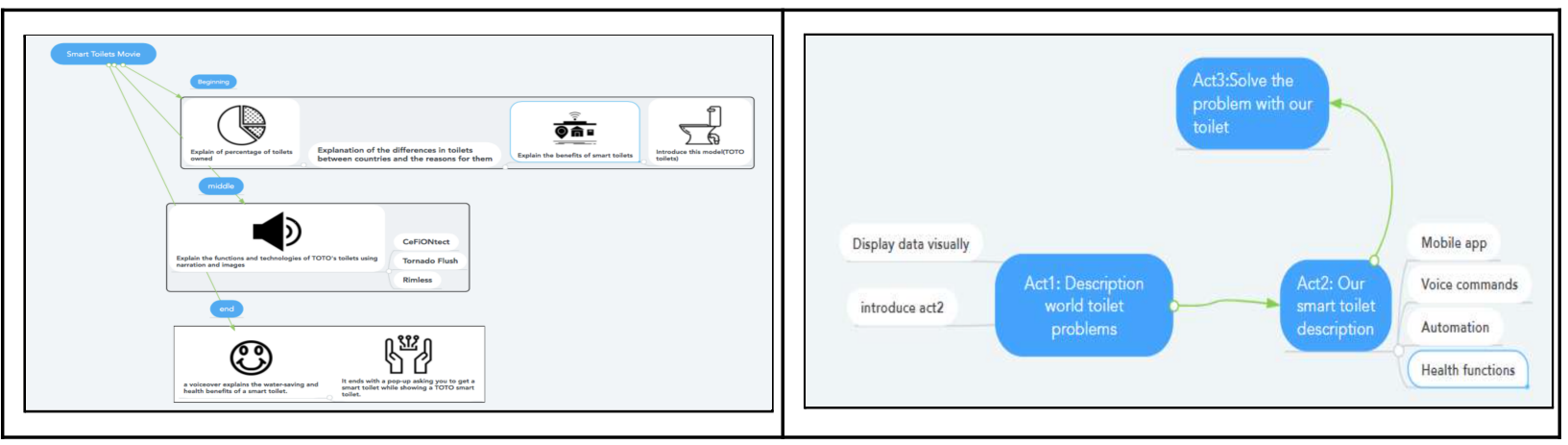

Figure 3A. Sketchboarding \& MindMeister - Group A

Figure 3B. Sketchboarding \& MindMeister - Group B

Table 8. Assignment 4: Sketchboarding and MindMapping - Score (Score out of 20)

\begin{tabular}{|l|c|c|}
\hline Criteria & Team A & Team B \\
\hline Breadth & 2 & 3 \\
\hline Interconnectivity & 2 & 2.5 \\
\hline Use of Descriptive Links & 1.5 & 2 \\
\hline Layout & 2 & 2.5 \\
\hline Development over Time & 2 & 2 \\
\hline
\end{tabular}

Outstanding $=4$, Very Good $=3$, Good $=2 ;$ Acceptable $=1$ and Unacceptable $=0$

\subsection{Assignment 5: Storyboarding Design}

This assignment (Table 9) provided an opportunity to explore how a directorial team could possibly see the story unfolding on screen - what is shown, the dialogues for each frame/scene, and how the sequence of the storyline on screen could possibly be managed.

Table 9. Assignment 5 Outline

\section{Assignment 4: Storyboarding Design}

Go back to Week 1 and 2, and read the screenplay and basic storyline carefully.

As part of this storyboarding exercise, use the https://wonderunit.com/storyboarder/ to design all the separate scenes that you would like to shoot for your movie.

* If you cannot download the scenes from the software and save as an image file, then take a screen capture (shift + command

+4 ) for each scene after you are done drawing.

** Use the storyboard assignment instructions sheet as a reference to complete this assignment.

Follow the instructions below:

1. Create a sketch for each major scene. You must create 8-10 scenes in TOTAL.

2. For each scene frame, write a 3-sentence caption in English explaining what is happening or what is being shown.

3. Also, for each of the above scenes, write two sentences each explaining the following: (A) environment, (B) mood, (C)

tone, (D) non-verbal gesture, (E) costume (F) characters, and $(\mathrm{G})$ camera angle and shot (long, short, medium shot, etc.)

4. Then write, at least 3-4 dialogues per sketch/scene to demonstrate who is saying and what?

5. Develop a complete sequence of events as it unfolds. Provide a short title for each scene.

*** Your 30-minutes movie must have at least 25-30 major scenes in the minimum.

6. Now use the Storyline creator software to complete the details about the characters, scene, and notes formally.

https://www.storylinecreator.com/

The storyboarding design assignment (Figure 4A \& 4B) demonstrated that Team A did a better job than Team B in trying to divide the separate scenes in a logical way. While Team A demonstrated 9 scenes with what the narrator said and the accompanying visual demonstrating the idea, Team B focused on only 6 scenes with accompanying dialogues. 


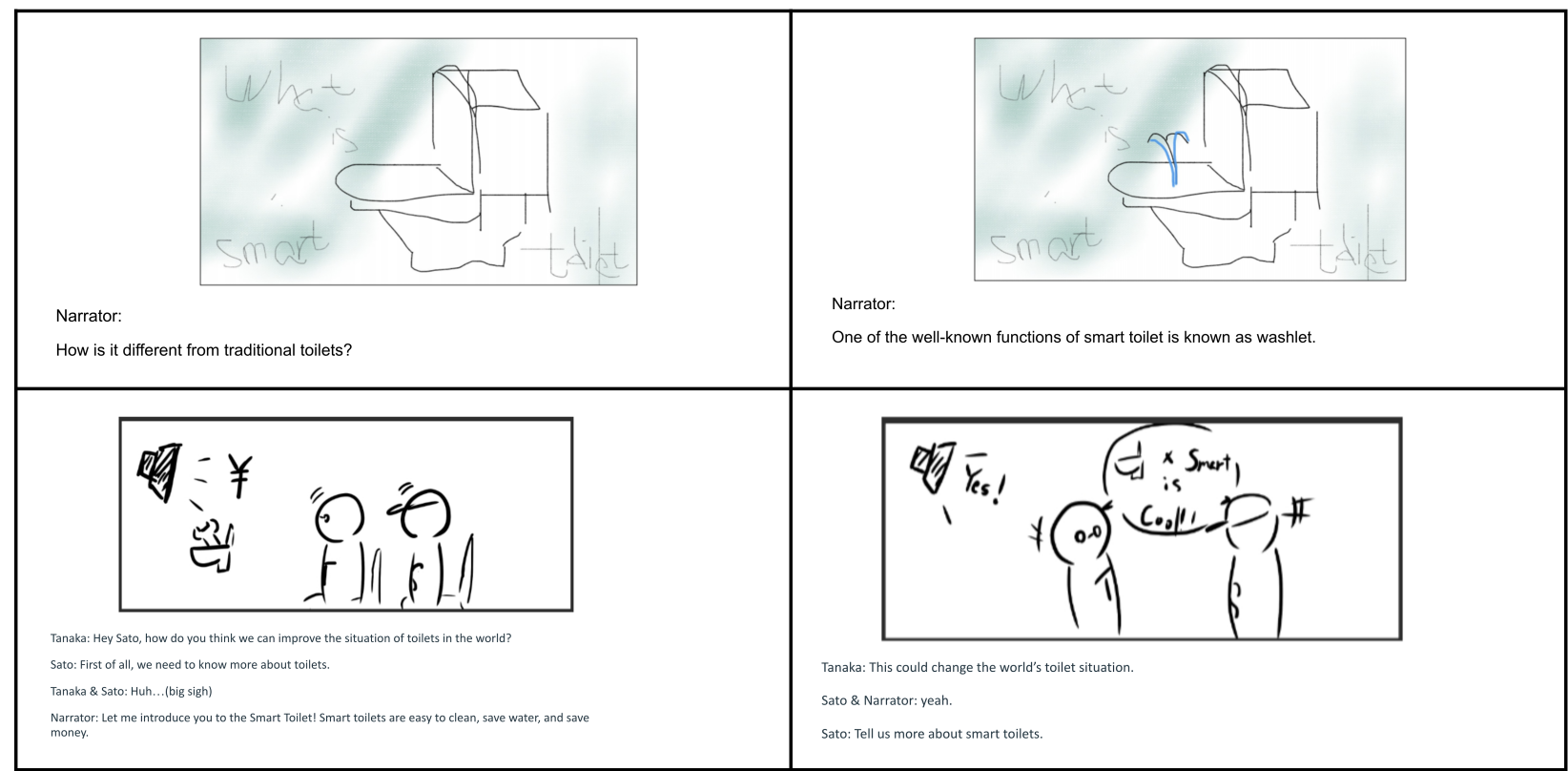

Figure 4A: Team A - Storyboarding Scenes

However, interestingly, at least retrospectively looking at the data available from Table 6 (Adobe Spark movie), it does not seem that students in Team A could flush out the ideas for the whole movie as yet, and/or couldn't quite develop a plan as how to connect the storyboarding design with the actual movie shooting. It's probably quite expected at this level with students having little or no experience of the field.
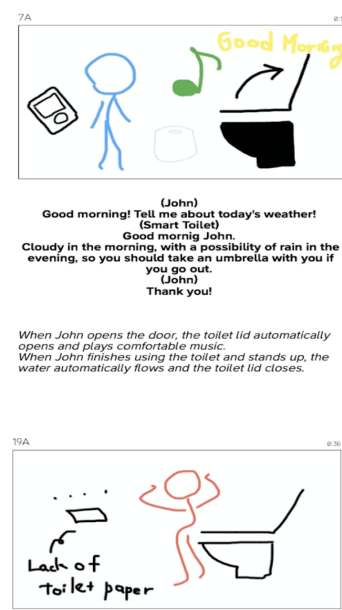

(Yuko) Today was very tired.

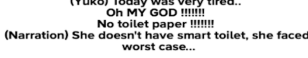

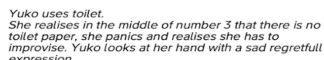
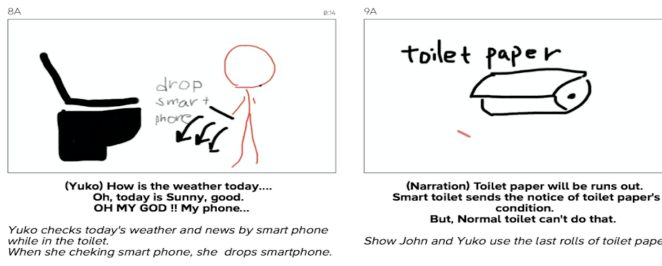

But, Normal tondition can can't do that
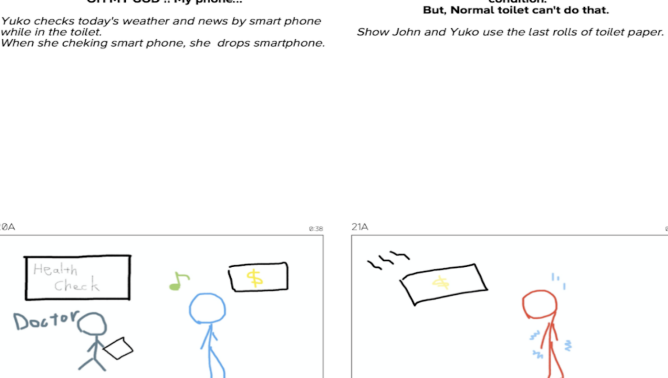

(Narration) Next day. he go to health check.Because of his heatth condition by smart toilet heath care

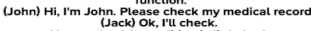

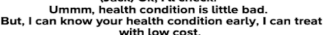
(John) ohit, thats cosce. Thanks

John goes to drug store
Jack gives John advice

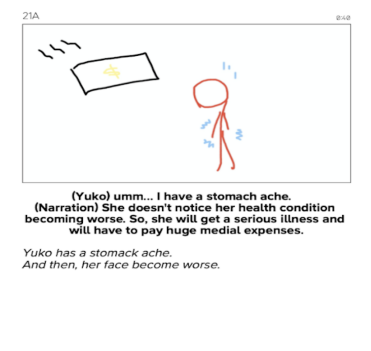

Figure 4B: Team B - Storyboarding Scenes

\subsection{Assignment 6: Conference Presentation of the Pre-Production Movie Plan}

The final assignment for the course was the conference presentation, where students prepared a PowerPoint/Keynote presentation summing up all the assignments they did for the course. It was guided by the course instructor with a clear outline mentioning how the data should be presented. All the team members participated and took their turns 
with specific slides to make the presentation. Team B performed better in terms of fluency of the presentation, layout and organization of the slide content, and working as a team to deliver the presentation.

\subsection{Teamwork Peer Review: Member Scores for 5 Major Assignments}

As a final course exercise, students were asked to rate their peers in the team for the 5 major assignments where they worked together as a team. Table 10 and 11 demonstrated how each student rated the performance of their team members, including themselves. Supporting the previous assignment scores, it appeared that students in Team B were both more objective about the contribution of their peers, and more aware of who contributed and to what extent. It's interesting that members in Team A were more confident overall with the team members participating in a positive way with the majority of the assignments, but Team B members did not shy away from identifying students who they thought did not contribute to the extent or in a way expected. This should be seen in the light of the performance data that shows overall, a better performance for Team B.

Table 10: Assignment-Specific Contribution for Team A (Frequency Scores for Categories)

\begin{tabular}{|c|c|c|c|c|c|c|}
\hline Assignment & Outstanding & Good & Moderate & Poor & $\stackrel{\text { No }}{\text { Contribution }}$ & Not Sure \\
\hline 2 & 13 & 42 & 5 & 1 & 0 & 6 \\
\hline 3 & 13 & 40 & 8 & 2 & 0 & 0 \\
\hline 4 & 19 & 41 & 2 & 0 & 0 & 1 \\
\hline 5 & 9 & 50 & 3 & 1 & 0 & 0 \\
\hline 6 & 15 & 46 & 11 & 0 & 1 & 0 \\
\hline Total & 69 & 219 & 29 & 4 & 1 & 7 \\
\hline
\end{tabular}

Table 11: Assignment-Specific Contribution for Team B (Frequency Scores for Categories)

\begin{tabular}{|c|c|c|c|c|c|}
\hline Assignment & Outstanding & Good & Moderate & Poor & No Contribution \\
\hline 2 & 28 & 22 & 15 & 1 & 3 \\
\hline 3 & 28 & 25 & 4 & 3 & 1 \\
\hline 4 & 26 & 28 & 12 & 0 & 3 \\
\hline 5 & 24 & 26 & 9 & 3 & 7 \\
\hline 6 & 35 & 25 & 1 & 3 & 18 \\
\hline
\end{tabular}

It's very important to understand how students accepted the course, and where they emphasised in terms of learning professional communication with movie production activities. Table 12 data suggests that overall, students focused on and saw the assignments in terms of the coordination and communication with the movie design team. They saw the major benefits resulting from such coordination and communication when undertaking the group movie design and pre-production activities.

The final outcome of such pre-production activities was the conference presentation. Data in Table 13 demonstrated that students were overall satisfied with their own and the group performance across both the teams, but some students saw moderate room for improvement for both their own performance and for the group. 
Table 12: Importance of Movie Design as an Important Way to Learn Professional Communication: Selected Comments

\begin{tabular}{|l|c|c|c|c|}
\hline Focus of the Comments & Frequency & View - Positive & View - Negative & Importance \\
\hline General Communication Skills & 2 & 2 & 0 & 1 \\
\hline Movie Design Activities & 2 & 2 & 0 & 3 \\
\hline Coordinating with Movie Design Team & 8 & 7 & 0 & 2 \\
\hline Communication with Movie Design Team & 7 & 7 & 0 & 3 \\
\hline $\begin{array}{l}\text { Content for Movie Design \& Connection to } \\
\text { Professional Communication }\end{array}$ & 5 & 4 & 1 & 0 \\
\hline Work in English & 1 & 1 & 0 & 0 \\
\hline
\end{tabular}

- The frequency highlighted the number of comments focused on the specific categories mentioned above

- Many of the comments addressed multiple categories simultaneously

Table 13: Rating of Own \& Group's Conference Presentation

\begin{tabular}{|l|c|c|c|c|c|}
\hline & Outstanding & Good & Moderate & Poor & No Contribution \\
\hline Own & 1 & 11 & 2 & 1 & 0 \\
\hline Group's & 1 & 11 & 3 & 0 & 0 \\
\hline
\end{tabular}

Table 14: Problems/Good Experience/Learning with Group Work in the Course: Selected Comments

\begin{tabular}{|l|}
\hline \multicolumn{1}{|c|}{ Comments } \\
\hline Almost all of our members did task proactively especially, $* * * *$ improved our documents. \\
\hline I wouldn't have joined this assignment. But I experienced working together with many friends. This experience was so good. \\
\hline $\begin{array}{l}\text { Everyone worked together to come up with ideas and try to make the documents better. However, the design of session } 5 \text { was } \\
\text { concentrated on one person. }\end{array}$ \\
\hline $\begin{array}{l}\text { The first group assignment was a bit difficult to understand until we got additional explanation and examples. Language } \\
\text { barrier (used Google translate, chatbot translator in slack and help from friends). Good experience; completing the conference } \\
\text { slides and presentation. Learning to coordinate, and task allocation were good experiences. }\end{array}$ \\
\hline $\begin{array}{l}\text { We had communication on the Internet. It worked for our team; we could communicate very well. Face-to-face } \\
\text { communication was more productive than online communication. }\end{array}$ \\
\hline $\begin{array}{l}\text { We were not friends with each other. So, ice-breaking was the biggest challenge. Other problems such as “what should we } \\
\text { do?" and "what should we design?" were solved by cooperating. }\end{array}$ \\
\hline $\begin{array}{l}\text { Each person's work was different; opinions were disjointed. So, it was hard to grasp their progress. However, I learned } \\
\text { something from this experience. }\end{array}$ \\
\hline $\begin{array}{l}\text { I think that each of us produced a good product for the role we were assigned. We were also able to improve our efficiency by } \\
\text { sharing information with each other. }\end{array}$ \\
\hline
\end{tabular}

The Table 14 data complemented the observations made in Table 12 with the majority of the focus being on group coordination, language barrier, project management and internal communication. Interestingly, in spite of the 
difficulties they saw the overall experience positively in most cases, and found adequate reasoning behind the assignments and the associated experience that resulted.

Table 15: Problems/Good Experience/Learning with Document Integration Exercise in the Course: Selected Comments

\begin{tabular}{|l|}
\hline \multicolumn{1}{|c|}{ Comments } \\
\hline Although we didn't co-edit it, we were able to create it in a way that didn't stray too far from the main idea \\
\hline $\begin{array}{l}\text { I feel it's difficult to choose which sentences are deleted or are adopted. You cannot know who is editing what because it } \\
\text { appears anonymous. }\end{array}$ \\
\hline $\begin{array}{l}\text { It's easy to manage files; good for collaborative work. But sometimes there were integration problems, but these were } \\
\text { probably not serious problems. }\end{array}$ \\
\hline $\begin{array}{l}\text { We could use Google Drive and SNS Slack effectively. By using it, we could confirm which task has not ended, and instruct } \\
\text { through SNS. }\end{array}$ \\
\hline Everyone in the group could edit it, so if you don't check the slides frequently, there will be omissions. \\
\hline I thought Google was very useful. Because we could work together despite not being together. It helped. \\
\hline I didn't have an important central role but we could make high-quality documents because of support from group members. \\
\hline $\begin{array}{l}\text { It was nice to be able to share everyone's project instantly. It was motivating because we could see that they were editing each } \\
\text { other in real time. }\end{array}$ \\
\hline
\end{tabular}

Data in Table 15 clearly identified some major issues resulting from the pre-production activities such as document integration and coordination between team members. Similarly, Table 16 identified some major issues with the range of software used that students confronted, and about which they had positive or negative feelings.

Table 16: Problems/Good Experience/Learning with the Software in the Course: Selected Comments

\begin{tabular}{|l|}
\hline \multicolumn{1}{|c|}{ Comments } \\
\hline The presentation didn't have to be done with Adobe Spark. But it could be any other software if you could create it. \\
\hline $\begin{array}{l}\text { Using Mind Mapping and Storyboarding software was difficult. We used a lot of software, and some were difficult. But } \\
\text { overall, a good experience. }\end{array}$ \\
\hline $\begin{array}{l}\text { DigiSigner (free online signature service) was a little inconvenient. Once I save a file, I cannot rewrite it. It seems that Group } \\
\text { A did not use Digisigner when completing the screenplay design worksheet. }\end{array}$ \\
\hline $\begin{array}{l}\text { I had a hard time getting used to some software that I didn't know how to use. It was interesting because I had a lot of } \\
\text { software to use for the first time. }\end{array}$ \\
\hline $\begin{array}{l}\text { Problems: Some of the software was not free for the full version. Good experience: learning movie making software, } \\
\text { sketchboard is good even for outside class usage i.e., making a mind map to show relations and connections. }\end{array}$ \\
\hline We used various applications to do our assignment. I took much time to remember how to use the applications. \\
\hline $\begin{array}{l}\text { The software we used in an online meeting with German students was interesting. We had thought that we would use zoom } \\
\text { and so was confused. }\end{array}$ \\
\hline Almost all the software was easy to use. But they were free versions, and so was a little inconvenient. \\
\hline
\end{tabular}


Data from Tables 17 and 18 were noteworthy as the comments will be considered, and would help the course instructor revise the course for the next time it's offered.

Table 17: Identification of How to Improve the Course: Selected Comments

\begin{tabular}{|l|}
\hline \multicolumn{1}{|c|}{ Comments } \\
\hline I think we need more explanation of how to use the software. I wanted to give feedback on the assignments. \\
\hline $\begin{array}{l}\text { We wanted to see examples of previous work. What our seniors have made, and a design sheet to know how they had } \\
\text { continued. }\end{array}$ \\
\hline Evaluation meeting and reflection meeting of the created movie would have been good. \\
\hline $\begin{array}{l}\text { I wanted you to make dividing assignments for the teams easier. There were some issues that were hard to separate. Some } \\
\text { software was a little difficult to use (e.g., Mind Meister). }\end{array}$ \\
\hline $\begin{array}{l}\text { I wanted to do movie production and presentation in face-to-face classes. I wanted to make a 20-30 minutes movie on a free } \\
\text { theme. I also wanted to directly talk with group members about movie making. }\end{array}$ \\
\hline Each group should have a zoom account. It's easy to communicate remotely. Introduce file integration tools. \\
\hline $\begin{array}{l}\text { Have example/reference material to visualise explained details. Have a more efficient monitoring system to know who did } \\
\text { what, especially for group tasks since one group only handles one task i.e., Poster } 1 \text { group, Poster } 2 \text { group, movie group. }\end{array}$ \\
\hline Minimize the amount of time spent explaining, and increase the amount of time they can help support the work. \\
\hline
\end{tabular}

Table 18: What was learnt from the Course? (not only language skills, but related to group work, technical writing and documentation, project-based activities, working in drafts including collaborative writing, etc.)

\section{Comments}

I feel I learnt many things from this course. I learnt the importance of teamwork and how to use many software, technical writing etc. I learnt the importance of communication.

Difficulties on how to move forward as a leader with a team on tasks; how to deal with delays. In summary I learnt about the difficulties of team activities.

Efficient activities as an organization and combining the ideas of others with your own ideas to create better ones.

I could learn how movies are made. Also, groupwork with unfamiliar people was a little hard, but exciting. I think this was a good experience. I also reminded myself that communication is very important in making things.

Of course, I learnt English but was also very happy to make movie posters, documents, and presentations. I especially had a sense of fulfillment when we presented our movie projects online.

Discussion, combining ideas, integration of movie files, documents, design etc. I think these are useful in companies.

Divide and conquer is a good strategy to use for groups. Evaluating contributions is not very easy without a yardstick. Always ask if you are not sure. Technology can help overcome communication barriers.

Difficulties in checking the progress of team work. I did group work with international students for the first time. Thanks to him for being frank - our presentation was even better.

One important aspect definitely was the range of software used, which probably could be cut down reasonably to focus on a few, but at the same time, it's important to understand that these software served different purposes, and is focused on developing different kinds of skill set. So, any curriculum revision has to consider the balance between 
information overload, and developing the necessary skill set. Another point was the group coordination. Because of the lack of experience with project management, some students ended up being more frustrated with the experience because of the non-functional or moderately-functional team members, the learning curve with the software, coordination with the team members, and the fact that no concrete example of the end product from previous students were not made available. Since this course, on the specific topic (smart toilet) was offered just as a case study and the topic changes every year, no final product was available from previous student groups. However, the idea was also to make them available plenty of professional and commercial video examples to learn from their English communication styles, presentation styles, movie design plan for commercial purposes etc. These couldn't have been possible from student projects done earlier in this environment.

\section{Discussion and Conclusion}

Although as part of this course, a promotional movie as a final end product was not feasible given the time constraints and group project experience, the process of undertaking the series of pre-production assignments was itself very fruitful when the goal was to promote professional communication and project management skills. Even when we consider the frustration that was associated with the communication and coordination lapses in the group, the experience of it all was worth it.

The low score for Team A could be attributed to lack of coordination between team members, incomplete assignments completed, no real all-round participation in Google docs. Apparently, the in-class discussion in both the groups were satisfactory, and happened in a participatory environment. However, one difference between Team $\mathrm{A}$ and $\mathrm{B}$, was the active responsibility taken up by various group members with higher levels of English language proficiency, and others worked around them to make the assignment successful and complete. But the assessment was still limited in scope in trying to understand what worked, and what did not, and how professional communication skills developed during the pilot project.

For a larger and robust study with a completed movie project, a Google Forms questionnaire could be used to test the perception of students about their impressions of their own videos, the complexity of the tasks and steps during movie-making, comparison with high-level commercial production, and their own confidence levels completing the tasks. A self-reporting questionnaire could be used to explore and gather data on students' own perception of meaningful learning through video production-supported project based learning (PBL), based on the TML model explained in Figure 1, in such a technical EFL-based university. The two questionnaires mentioned above, when investigated in combination, could help explore how and the extent to which an entrepreneurship-based education in a PBL context could be successfully introduced in a video-production based EFL teaching curriculum.

The TML model, in the original case [18], and for our project reported on a design-based research for designing, implementing, and refining a problem-based learning (PBL) course on educational digital video (promotional digital video, in our case). Much like the original research [18], this course too builds on a combination of problem-solving in small group tutorial sessions and realizing a practical hands-on project during which the students design and produce educational videos about the topics they are studying. However, interestingly, the class was conducted in a blended format both online (with Zoom), and face-to-face meetings with extensive use of the chat line for in-class discussions and decision-making, Google Drive, and Moodle as the LMS.

Previous experience with similar coursework with a different content area (3D printing, LEGO design etc.), initial assessment and preliminary project outcomes including zoom-based course discussion suggested that students are capable of handling the project successfully with good understanding of the product and the market based on course lecture materials (video, company websites, readings etc.).

Some of the recommendations and planned revisions for the future versions of the course could possibly include cutting down on the number of software used in a way that makes sense, or use explicit training videos and in-class guidance for each of the software that directly leads to the software functions being used for the course assignments. Secondly, the group coordination has to be better managed. From next time, the group lead will be asked to make tracked edits in Google Docs, pop open the 'Editing' menu at the top right hand corner of their document. The Google Doc will then function exactly as a Word Doc when 'Track Changes' are turned on. The group lead will be able to see who made the change, when they made it and what the change was. The class participation grade will consider that data, and it will also be matched to self-reported data for research purposes.

Another interesting point under consideration is to ask the student groups to video record their in-class group conversations in English as a graded assignment in systematically designed sessions, followed by regular unstructured Japanese conversations. This is directly linked to professional communication. Such an initiative will not only allow students to speak in English, but will also increase their self confidence and enhance their experience of working in groups. 
Finally, we would like to consider the opportunity for explicit feedback from marketing experts who could evaluate the planned design of the movie when the final conference presentation is delivered, or as part of a different and more advanced course in movie design. There is research supporting such an idea. Soft skills, especially communication skills, are important skills which each graduate must possess. Accordingly, several courses and approaches have been carried out in universities to train students in communication skills. The skills are normally evaluated by course lecturers. However, assessments by a third party from outside the university are valuable so that the students' achievements may be weighed against external evaluators' point of views [19].

This preliminary pilot study was more about identifying the issues, problems, achievements and successes. The broad idea of the project is consistent with the literature which is aimed at teaching students how to solve problems with technology [20].

\section{References}

[1] Nikitina, L. (2010). Video-making in the foreign language classroom: Applying principles of constructivist pedagogy. Electronic Journal of Foreign Language Teaching, 7(1), 21-31.

[2] Masats, D., Dooly, M., \& Costa, X. (2009, July). Exploring the potential of language learning through video making. In Proceedings of EDULEARN09 Conference. Valencia, Spain: International Association of Technology, Education and Development (IATED).

[3] Goldfarb, B. (2002). Visual pedagogy: Media cultures in and beyond the classroom. Durham: Duke University Press.

[4] Blin, F. (1999). CALL and the development of learner autonomy. In R. Debski \& M. Levy (Eds.), WorldCALL: Global perspectives on computer assisted language learning (pp. 133-147). Lisse: Swets \& Zeitlinger.

[5] Carney, N., \& Foss, P. (2008). Student-Produced Video: Two Approaches. In English Teaching Forum (Vol. 46, No. 2, pp. 14-19). US Department of State. Bureau of Educational and Cultural Affairs, Office of English Language Programs, SA-5, 2200 C Street NW 4th Floor, Washington, DC 20037.

[6] del Rosario, P. (2010). Lights, Camera, Action! Student-produced Videos in an English Language Program.

[7] Roy, D. (2017). Developing a project-based CALL environment with technical communication in an exploratory 3D printing context. International Journal of Computer-Assisted Language Learning and Teaching (IJCALLT), 7(2), 75-101.

[8] Roy, D., \& Crabbe, S. (2017, June). 3D printing with critical thinking and systems design: an innovative approach to task-based language teaching in technical communication. In CALL in CONTEXT: XVIIIth International CALL Research Conference (pp. 650-657).

[9] Roy, D. (2018, July). A Model for Language Learning with Crowdsourcing and Social Network Analysis for Community Decision-Making. In Proceedings of the 2nd International Conference on Education and Multimedia Technology (pp. 14-19).

[10] Liu, C., Yu, H., Dong, Y., Shen, Z., Yu, Y., Dixon, I., ... \& Cui, L. (2020, April). Generating Engaging Promotional Videos for E-commerce Platforms (Student Abstract). In Proceedings of the AAAI Conference on Artificial Intelligence (Vol. 34, No. 10, pp. 13865-13866).

[11] Karjaluoto, H., Ulkuniemi, P., \& Mustonen, N. (2015). The role of digital channels in industrial marketing communications. Journal of Business \& Industrial Marketing.

[12] Fong, Y. L., Firoz, D., \& Sulaiman, W. I. W. (2018). The impact of tourism advertisement promotional videos on young adults. e-Bangi, 14(3). 
[13] Guerrero-Rodríguez, R., Stepchenkova, S., \& Kirilenko, A. (2020). Experimental investigation of the impact of a destination promotional video with physiological and self-reported measures. Tourism Management Perspectives, 33,100625 .

[14] Verhoef, P. C., Stephen, A. T., Kannan, P. K., Luo, X., Abhishek, V., Andrews, M., ... \& Hu, M. M. (2017). Consumer connectivity in a complex, technology-enabled, and mobile-oriented world with smart products. Journal of Interactive Marketing, 40, 1-8.

[15] Meyer, G. G., Främling, K., \& Holmström, J. (2009). Intelligent products: A survey. Computers in industry, $60(3), 137-148$

[16] McMurray, J. (2014). Rubric for assessing concept maps. University of Waterloo, California, available in https:/uwaterloo.ca/centre-for-teaching-excellence/teachingresources/teaching-tips/assessing-student-work/gradingandfeedback/rubric-assessing-concept-maps. [accessed in 05/02/2014]

[17] Coutinho, E. (2014). Concept maps: evaluation models for educators. Journal of Business and Management Sciences, 2(5), 111-117.

[18] Hakkarainen, P. (2011). Promoting meaningful learning through video production-supported PBL. Interdisciplinary Journal of Problem-based Learning, 5(1), 4.

[19] Kamal, N., Arsad, N., Rahni, A. A., Yahya, I., IBRAHIM, W., \& Shaarani, M. F. (2014). Students' Communication Skills Assessment by External Lecturers and Industry Representatives. Journal of Engineering Science and Technology Special Issue on PEKA 2016, November. 69 - 77 (C) School of Engineering, Taylor's University.

[20] Jonassen, D.H., Howland, J., Moore, J., \& Marra, R.M. (2003). Learning to solve problems with technology: A constructivist perspective. Upper Saddle River, NJ: Merrill. 